\title{
MESOSCALE ATMOSPHERIC MODELING OF ACCIDENTAL TOXIC AND RADIOACTIVE RELEASES FOR EMERGENCY
} RESPONSE AT SRS (U)

by B. L. O'Steen

Westinghouse Savannah River Company

Savannah River Site

Aiken, South Carolina 29808

Other Authors:

J. D. Fast

(WSRC)
WSRC-RP- $-92-868$

DE93 005297

This paper was prepared in connection with work done under Contract No. DE-AC09-89SR18035 with the U. S. Department of Energy. By acceptance of this paper, the publisher and/or recipient acknowledges the U. S. Government's right to retain a nonexclusive, royalty-free license in and to any copyright covering this pe.per, along wit the right to reproduce and to authorize others to reproduce all or part of the copyrighted paper.

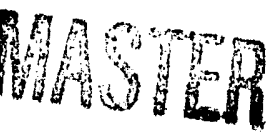




\section{DISCLAIMER}

This report was prepared as an account of work sponsored by an agency of the United States Government. Neither the United States Government nor any agency thereof, nor any of their employees, makes any warranty, express or implied, or assumes any legal liability or responsibility for the accuracy, completeness, or usefulness of any information, apparatus, product, or process disclosed, or represents that its use would not infringe privately owned rights. Reference herein to any specific commercial product, process, or service by trade name, trademark, manufacturer, or otherwise does not necessarily constitute or imply its endorsement, recommendation, or favoring by the United States Government or any agency thereof. The views and opinions of authors expressed herein do not necessarily state or reflect those of the United States Government or any agency thereof.

This report has been reproduced directly from the best available copy.

Available to DOE and DOE contractors from the Office of Scientific and Technical Information, P.O. Box 62, Oak Ridge, Tis 37831; prices available from (615) 576-8401, FTS 626-8401. 
WSRC-RP-92-868

MESOSCALE ATMOSPHERIC MODELING OF ACCIDENTAL TOXIC AND RADIOACTIVE RELEASES FOR EMERGENCY RESPONSE AT SRS (U)

B.L. O'STEEN aild J.D. FAST

Publication Date: June 30, 1992

Westinghouse Savannah River Company Savannah River Site

Aiken, SC 29808 


\title{
MESOSCALE ATMOSPHERIC MODELING OF ACCIDENTAL TOXIC AND RADIOACTIVE RELEASES FOR EMERGENCY RESPONSE AT SRS
}

\author{
By B. L. O'Steen and J. D. Fast \\ Westinghouse Savannah River Company \\ Savannah River Site \\ Aiken, SC 29808
}

\section{SUMMARY}

In August of 1991, the Environmental Transport Group (ETG) began the development of an advanced Emergency Response (ER) system based upon the Colorado State University Regional Atmospheric Modeling System ${ }^{1}$ (RAMS). This model simulates the threedimensional, time-dependent, flow field and thermodynamic structure of the planetary boundary layer (PBL). A companion Lagrangian Particle Dispersion Model2 ${ }^{2}$ (LPDM) simulates contaminant transport based on the flow and turbulence fields generated by RAMS. The long-term objectives and milestones of this project were proposed and discussed in detail in a previous report ${ }^{3}$. The current report describes progress to date on this project in the areas of data development, data assimilation, and operational (real-ime) procedures. In particular, a diagnostic capability for simulating contaminant transport is demonstrated. This fulfills a FY 1992 DOE milestone for the Environmental Technology Section (ETS) of the Savannah River Technology Center.

At this time, the atmospheric transport of contaminants from SRS can be determined from the above models in a post-accident analysis, using all available regional and local meteorological data. This diagnostic capability is demonstrated by simulating a hypothetical, 12-hour release for June 3, 1992. National Meteorological Center (NMC) large-scale model data, regional National Weather Service (NWS) observations and local SRS tower data were used as input to the RAMS code. Data assimilation techniques were used to incorporate SRS tower data into the model for the entire simulation period. Results for windfields and particle transport at 6hour intervals are presented along with SRS tower observations.

Developing this capability has provided the basis for the next phase of development of the advanced ER system. This system will be run in two modes of operation to demonstrate its capability. In the first mode, a diagnostic calculation will be made by RAMS every hour based on the latest 15 minute data from SRS meteorological towers, and LPDM will be used to predict local contaminant transport within $50 \mathrm{~km}$ from the release location. In the second mode of operation, a fully prognostic calculation will be made by RAMS twice a day based on the initial conditions produced by the first mode of operation, and LPDM will be used to predict regional-scale contaminant transport. The 3-dimensional wind fields and the plumes produced 
by these two modes of operation will initially provide additional information and guidance for the existing transport codes used by the ETG.

\subsection{INTRODUCTION}

Atmospheric transport and diffusion models have been developed for real-time calculations of the location and concentration of toxic or radioactive materials during an accidental release at the Savannah River Site (SRS). These models employ one or two-dimensional measured wind characteristics to advect air-borne contaminants and assume Gaussian distributions to represent turbulent diffusion. These models have been incorporated into an automated menu-driven program called the Weather INformation and Display (WIND) System ${ }^{4}$. The assumptions employed by the WIND System atmospheric models allow the computations of the groundlevel concentration of toxic or radioactive materials to be made quickly; however, Gaussian models suffer from limitations because of the simplifications made to the governing equations. Nevertheless, most commercial emergency response models in use today employ the Gaussian assumption.

The WIND System atmospheric models are unique in that they incorporate a forecasted wind field, based on large-scale model results from the National Weather Service (NWS) Model Output Statistics (MOS) product. However, the MOS forecast wind field is only onedimensional. Thus, even with MOS forecast capability, the WIND System atmospheric model results have limited real-time regional capability due to spatial inhomogeneity unaccounted for in the forecast meteorological fields. A more realistic forecast, at both local and regional scales, requires prognostic, 3-D fields.

Three-dimensional, coupled atmospheric-dispersion models, such as RAMS and LPDM are not limited by the simplifications of the Gaussian diffusion assumption. These two models have been used in the past to predict the transport of pollutants in a variety of complex atmospheric circulations ${ }^{5,6}$ and the use of similar three-dimensional models in ER applications has been the subject of a recent symposium ${ }^{7}$. Unfortunately, models such as RAMS require large amounts of computational time when run with high resolution for a regional forecast. Full utilization in such an operational capacity is still not practical. However, advances in computer technology has made possible high-resolution, diagnostic calculations for local contaminant transport, and low-resolution, fully prognostic calculations for regional-scale contaminant transport.

The model development described in this report was necessary to complete the long-term objectives and milestones of the project listed in detail in a previous report ${ }^{3}$. One of these objectives was to create a version of the RAMS and LPDM models that could be used on demand for post-accident analysis purposes to produce three-dimensional wind, turbulence, and temperature fields and particulate transport forecasts. This objective has been completed as part of a DOE milestone for June, 1992. Another objective was to create an operational version of RAMS and LPDM by the summer of 1993. This report will also describe two prototype versions of the advanced ER system based on RAMS and LPDM that will be available by the end of August, 1992. These versions will be used to demonstrate that routine forecasts of 3dimensional wind, turbulence, and temperature fields and particulate concentrations can be made by the ETG for emergency response purposes at SRS.

\subsection{MODEL DEVELOPMENT}

\subsection{Data Development}

All models of physical processes depend on input data for initial conditions and or boundary conditions. Prognostic modeling of the planetary boundary layer depends on boundary 
conditions in a manner unique to flow models spanning domains smaller than hemispherical in size. Since the domain of the RAMS model configuration proposed for SRS (approximately $600 \mathrm{~km} \times 600 \mathrm{~km}$ ) has no true lateral boundary conditions, the numerical results of a largescale, hemispheric model are required to set time-dependent constraints on the domain boundaries. Initial conditions can be set with a single vertical profile of wind, temperature, and humidity; however, a long initial period may be required for the model to reach a dynamically balanced state. It is much better to initialize a mesoscale model such as RAMS with both largescale model data and as many surface and upper-air observations as possible. While spurious gravity waves may be produced by this initialization procedure, a balanced flow field is achieved in a relatively short time.

New and existing data sources have been develoned for atmospheric modeling with RAMS at SRS including:

(1) National Meteorological Center Model Data: The Nested Grid Model (NGM) is an atmospheric model used by the National Meteorological Center (NMC) to produce operational weather forecasts twice a day for North America. The output from the NGM model is accessed by the WIND System VAX computer via a 9600 baud modem link by an automated procedure that tests for data capture and retransmission. Three types of NGM data are accessed by the VAX computer including: (1) a 12 hour forecast on a horizontal grid with $90 \mathrm{~km}$ spacing and 13 vertical levels from the surface to approximately $50000 \mathrm{ft},(2)$ a 48 hour forecast on a horizontal grid with $190 \mathrm{~km}$ spacing and 10 vertical levels from the surface to approximately $50000 \mathrm{ft}$, and (3) a 48 hour forecast on a horizontal grid with $190 \mathrm{~km}$ spacing and 5 vertical levels from the surface to $5000 \mathrm{ft}$. Hourly forecast periods are available from data set (1); however, it is somewhat limited for ER purposes since it becomes available 6 hours after the NGM forecast run is initiated. Data sets (2) and (3) contain forecasts at 6 hour intervals and data set (3) compliments (2) by providing additional vertical resolution in the PBL.

(2) National Weather Service Upper-Air and Surface Observations: Routine NWS upper air balloon soundings for 12 locations in the southeastern U. S. are automatically transmitted twice a day from the NWS AFOS computer to the WIND System VAX computer. Surface observations for 66 locations over the same region are transmitted every hour.

(3) SRS Meteorological Tower Data: Data from the WIND system meteorological towers, central climatology, and the WJBF TV tower are transmitted every 15 minutes to the WIND System VAX computer.

The NGM model output is a completely new data set that is available on the VAX computer. The NWS upper-air and surface observations, and SRS meteorological tower data are existing data sets; however, additional files have been written to archive the data in a format that can be utilized by the IBM RS/ 6000 workstations in an UNIX environment. All of the data described in (1) - (3) will be archived on each workstation used for ER. In this way, a natural and desirable workstation independence is achieved. Thus, even if the network for transmitting data and/or an individual workstation fails, ER capability will not be impaired.

The initial conditions for RAMS are calculated by a companion model, ISentropic ANalysis (ISAN), and are based on the large-scale NGM model output, and upper-air and surface observations. Unfortunately, it is not feasible to include high-resolution meteorological observations, such as those available from the SRS meteorological towers, in the initial conditions generated by the current version of ISAN. Data assimilation techniques provide a method for incorporating meteorological observations (including high-resolution data) in to the model results over an extended period of time. This technique has been incorporated in RAMS to generate better initial conditions for a forecast and to provide a meshing of model results with observations for optimal diagnostic fields for ER purposes. 


\subsection{Data Assimilation}

Four-dimensional data assimilation (4DDA) is a technique for utilizing observations over an extended pre-forecast period to optimize initial conditions for a forecast simulation. However, 4DDA techniques have received a great deal of attention recently not only to improve the initial conditions of mesoscale forecast models, but to create high-quality four-dimensional mesoscale analysis fields that can be used as input to air-quality models. Several 4DDA techniques have been recently developed to incorporate high-resolution asynoptic observational data into atmospheric model forecasts ${ }^{8}$. One of those techniques is Newtonian relaxation, in which the model variables are gradually driven, or nudged, toward the observations by extra forcing terms in the governing equations. Although it is less rigorous than state-of-the-art techniques such as Kalman-Bucy filtering or the adjoint method, Newtonian relaxation is more practical due to its simplicity and less demanding computational requirements. Newtonian relaxation has been used with some degree of success to assimilate data into mesoscale models ${ }^{9,10}$, and more recently, into mesoscale models in regions of highly-complex terrain 11,12 . The results of these studies have indicated that improved initial conditions and forecasts can be generated by this technique.

A four-dimensional data assimilation technique based on Newtonian relaxation is used for the ER application so that data from the SRS meteorological towers can be incorporated into the 3dimensional wind fields produced by RAMS. The additional code for this method was developed and tested by the ETG during FY 1992. This task has been completed over a year ahead of schedule, according to the original objectives and milestones of this project ${ }^{1}$. The code has been evaluated using data taken from one experiment of the DOE's Office of Health and Environmental Research (OHER) program Atmospheric Studies in COmplex Terrain (ASCOT) along the front range of the Rockies in Colorado ${ }^{13}$. The dispersion of non-buoyant particles and the predicted surface concentrations were also compared to tracer data taken from the 1.991 Winter Validation Study (WVS) conducted by EG\&G Rocky Flats personnel ${ }^{14}$. One of the reasons the ASCOT program was established was to develop techniques for predicting transport and diffusion of pollutants in complex terrain for emergency response needs. The results of the study performed by ETG indicated that four-dimensional data assimilation was able to produce high-resolution mesoscale analysis fields that could be used to predict the transport and diffusion of pollutants.

Scientists participating in the South Carolina University Research and Educational Foundation (SCUREF) arrangement are currently examining state-of-the-art data assimilation techniques. Shun Der Ko's group from the Department of Geological Sciences at the University of South Carolina is examining the Kalman-Bucy filtering technique for RAMS. Roger Pielke's group from the Atmospheric Sciences Department at Colorado State University is examining the adjoint method for RAMS. These advanced data assimilation methods will probably become available and computationally practical to use for ER applications sometime in the next few years.

\subsection{Operational Procedures}

Operational mesoscale modeling of pollutant transport will become increasingly practical as computational costs decrease and additional data from high-resolution remote sensing instrumentation networks become available during the 1990's. The research and development being performed by the Environmental Transport Group for the ER application will be used to predict the atmospheric transport of airborne materials from SRS. However, the modeling procedure described in this section could also be adapted for use at other DOE facilities with a potential for atmospheric releases. 
The advanced emergency response system at SRS will operate in two modes simultaneously. The first mode will be a diagnostic computation for local transport utilizing meteorological fields created by RAMS with continuous data assimilation. The second mode of operation will be a fully prognostic calculation for regional scale contaminant transport. The general computational resources available for the advanced ER system, the individual codes, and the input and output data is depicted in Figs. 1 and 2. Two computers, sich as those shown in Fig. 1, will be required for the proposed system. They will be connected via ethernet to the VAX 8550 which will be the database for NGM model output data, surface and upper-air observations from AFOS, and data from the SRS meteorological towers. As meteorological data is updated on the VAX computer, it will be automatically transmitted to all ER workstations. While two computers are required primarily for computational speed, they also provide additional ER backup.

The first mode of operation with a semi-prognostic version of RAMS will be utilized for high resolution, local transport forecasts. RAMS will be run in cycles lasting 24 hours initiating at 8 am each day. Automated procedures based on the UNIX operating system will control the timing of the execution. At 8 am, the ISAN package will generate the initial conditions for RAMS. Then RAMS will be executed to generate the initial conditions for the 24-hour cycle. One hour later at 9 am, RAMS will be executed for a 1-hour data assimilation period based on the initial conditions at 8 am and 4-15 minute periods of SRS meteorological tower data between 8 and 9 am. Unless a transport forecast is made with LPDM, RAMS will remain idle from the the end of the assimilation period until $10 \mathrm{am}$. Then another one hour assimilation forecast with RAMS will be made with the local SRS tower data from 9 to 10 am. This process is repeated every hour until 8 am the next morning. By running RAMS in this manner, the latest winds from the SRS meteorological towers are included in the local calculations to produce very accurate three-dimensional wind field over the site. Also, the planetary boundary-layer is allowed to grow realistically throughout the day. The product that would be available at any given time is a three-dimensional wind and temperature field that is at most one hour old.

In the first mode of operation, LPDM can be run at any time during the day with the latest 3dimensional wind field produced by RAMS. Constant winds (time-invariant) for a 3 hour period will be assumed to produce a forecasted plume direction and location. LPDM: could also be executed automatically at the end of each RAMS assimilation period to produce a hypothetical plume at any given time. The hourly three-dimensional wind fields produced by RAMS could also be used to construct time-dependent post-accident analysis.

It is anticipated that each one hour assimilation cycle will require $30 \mathrm{CPU}$ min. LPDM and graphic modules will probably require 5-10 CPU minutes, depending upon the type of output. With the current domain configuration, the data assimilation period can only be completed on a dedicated workstation as shown in Figs. 1 and 2. Other processes can be run at the same time on the system (such as X-windows, editing, small programs) if they do not slow the system such that it gets behind schedule.

The second mode with full prognostic capability will povide a long-range $(300 \mathrm{~km})$ forecast capability utilizing the $48 \mathrm{hr}$ NGM forecast to drive the RAMS and LPDM models. A new RAMS run will be initiated every 12 hours as an updated NGM forecast becomes available. For a 12 hour cycle, the actual forecast period produced by RAMS is given by $R \tau-t$ for $\tau<t<$ $12+\tau$, where $R$ is the ratio of simulation time to CPU time for RAMS and $\tau$ is the CPU time required for a simulation. If a minimum forecast period of 24 hours is desired, then $\tau(R-1)>$ 36. In this case the maximum forecast period is 36 hours. $\tau$ should be less than 12 hours to avoid overlap of RAMS computational cycles; this requires $R>4$. A computational (CPU) time of 6 hours demands $R>7$. These simulation/CPU time ratios place restrictions on the 
spatial resolution of the RAMS model for a given domain size and processor speed. At this time, a $10-20 \mathrm{~km}$ horizontal grid spacing is initially planned for the prognostic mode of the ER system.

Computational resource and network characteristics of the advanced ER system for both modes of operation include:

- VAX 8550 computer acts as a database for various meteorological data needed for the modeling system

- IBM RS/6000 model 550 workstation where the prototype operational modeling system will be executed

- IBM RS/6000 model 530h workstation where post-accident analysis forecasts can be made

- TCP/IP connection between IBM RS/6000 workstations and VAX 8550 computer

- $\quad$ NGM model output from NMC, surface and upper-air observational data from AFOS line, feed, and SRS meteorological tower data copied from VAX 8550 computer to the IBM workstation through the NFS protocol

Characteristics of RAMS for the first mode of operation of the advanced ER system include:

- $\quad 3$ nested grids with a resolution of $26 \mathrm{~km}$ grid $1,6 \mathrm{~km}$ on grid 2, and $2 \mathrm{~km}$ on grid 3

- $\quad$ time step of $20 \mathrm{~s}$

- $\quad$ one complete cycle of RAMS run is $24 \mathrm{hr}$ period

- $\quad$ one hour assimilation period incorporates the past 4 periods of $15 \mathrm{~min}$ data taken from the SRS meteorological towers

- data assimilation cycle and restart of model at each hour allows for a realistic development of the PBL

- $\quad$ NGM 48-hour forecasts are used to imprse large-scale variations in the flow on the RAMS model at the domain boundaries.

Characteristics of RAMS for the second mode of operation of the advanced ER system include:

- 1 grid with a resolution of $15 \mathrm{~km}$

- $\quad$ time step of $20 \mathrm{~s}$

- $\quad$ RAMS executed twice a day for a 48 hour forecast

- $\quad$ one hour assimilation period incorporates the past 4 periods of 15 min data taken from the SRS meteorological towers

- initial conditions obtained from data assimilation cycle obtained from the first mode of operation

- NGM 48-hour forecasts are used to impose large-scale variations in the flow on the RAMS model at the domain boundaries.

Current graphic capabilities include:

- $\quad$ NCAR graphics for two-dimensional output

- $\quad$ savi3D produced by SSESCO for high-quality three-dimensional, color graphics

- black and white hardcopy available on laserjet and copy hardcopy available on HP paintjet

\subsection{RESULTS}

A test case was performed to demonstrate the post-accident, diagnostic capability of the RAMS and LPDM models. RAMS was executed with all of the available meteorological data from the VAX computer as if a post-accident analysis calculation was to be made. The model was 
initialized at 8 am on June 3,1992 with the initial and boundary conditions specified using the large-scale results from the NGM model. A 12-hour forecast of the wind field was made in which the data from the meteorological towers were assimilated every 15 minutes during the entire forecast. A hypothetical plume was produced by assuming a continuous release between 8 am and $8 \mathrm{pm}, 61 \mathrm{~m}$ above the surface at the K-Reactor location.

The regional-scale wind field produced by RAMS for the 6 and 12 hour forecasts is depicted in Fig. 4. Southeasterly flow persisted over SRS for most of the day; however, a moderate amount of spatial inhomogeneity in the regional-scale wind field existed. The local wind field produced by RAMS and the instantaneous plume determined by LPDM at $2 \mathrm{pm}$ and $8 \mathrm{pm}$ is depicted in Fig. 5. The data from the meteorological towers used by RAMS at these two time periods is shown in Fig. 6 . The wind at $2 \mathrm{pm}$ was from the southeast, so the resulting plume traveled to the northwest. A significant amount of dispersion can be seen in the plume as it travels downwind. At $8 \mathrm{pm}$, the plume location shifted slightly to the north, but increased atmospheric stability in the PBL during the late afternoon caused the plume width to narrow as expected.

The vertical structure of the plume predicted by LPDM (not shown) indicated that the plume lifted $200 \mathrm{~m}$ above the surface $40 \mathrm{~km}$ downwind of SRS. This type of behavior can occur during the daytime when significant vertical velocities may transport the plume to higher levels in the atmosphere. In addition, substantial vertical wind gradients sheared the plume apart 40 $\mathrm{km}$ downwind of SRS. Both of these characteristics cannot be simulated by any of the current WIND System atmospheric models. It is important to note that on June 4, the local horizontal wind field was nearly uniform around SRS and dir not change significantly in time; therefore, the assumption a horizontal homogeneity in the WIND System atmospheric models would probably be satisiied in this case. The local horizontal wind field for other atmospheric situations may not be as simple. Numerical studies will be performed in the future to compare the output produced by the RAMS and LPDM models with the WIND System atmospheric models.

\subsection{CONCLUSION}

The ability to execute the RAMS and LPDM codes for post-accident analysis of both local and regional contaminant transport has been demonstrated. Large-scale, regional and local (SRS towers) data were all included in this analysis through initial conditions, time-dependent boundary conditions and periodic data assimilation. The result is an optimal diagnosis of atmospheric transport. A procedure for implementing these codes in an operational ER capacity has been defined based on the above input data. The software for executing the ER procedure is currently being developed and will be implemented in the near future; extensive testing will follow. In FY 1993, a dose routine will be developed for the LPDM code and work will begin on a deposition model.

\section{REFERENCES}

1. Tripoli, G. J, and W. R. Cotton. "The Colorado State University Three-Dimensional Cloud / Mesoscale Model - 1982, Part I: General Theoretical Framework and Sensitivity Experiments". J. Rech. Atmos. 16, pp 185-219 (1982).

2. McNider, R. T., M. D. Moran, and R. A. Pielke. "Influence of Diurnal and Inertial Boundary-Layer Oscillations on Long-Range Dispersion". Atmos. Environ. 22, pr 2445-2462 (1988).

3. Fast, J. D., B. L. O'Steen, and R. P. Addis. Development of an Advanced Atmospheric/Transport Model for Emergency Response Purposes. WSRC-RP-91-577, Savannah River Site, Aiken, SC 29808 (1991). 
4. Hunter, C. H. Weather Information and Display (WIND) System User's Manual. WSRC-TM-90-14, Savannah River Site Aiken, SC 29808 (1990).

5. Pielke, R. A., R. W. Arritt, M. Segal, M. D. Moran, and R. T. McNider. "Mesoscale Numerical Modeling of Pollutant Transport in Complex Terrain". Boundary Layer Meteor. 41, pp 59-74 (1987).

6. Pielke, R. A., M. D. Moran, M. Segal, D. A. Wesley, and T. B. McKee. "Opportunities for Nowcasting Air Pollution Episodes and Accidental Toxic and Radioactive Releases". Preprints, Proc. Symp. Mesoscale Analysis and Forecasting, Amer. Met. Soc., pp 463-470, (1987).

7. OCDE Nuclear Energy Agency (NEA). Proceedings of the Specialists; Meeting on Advanced Modelling and Computer Codes for Calculating Local Scale and Meso-Scale Atmospheric Dispersion of Radionuclides and their Applications, Paris, France, p 258, (1991).

8. Harms, D. E., S. Raman, and R. V. Madala. "An Examination of Four-Dimensional Data-Assimilation Techniques for Numerical Weather Prediction". Bull. Amer. Met. Soc. 73, pp 425-440 (1991).

9. Kao, C. J., and T. Yamada. "Use of the CAPTEX Data for Evaluations of a LongRange Transport Numerical Model with a Four-Dimensional Data Assimilation Technique". Mon. Wea. Rev. 116, pp 293-305 (1988).

10. Stauffer, D. R., and N. L. Seaman. "Use of Four-Dimensional Data Assimilation in a Limited Area Mesoscale Model. Part I: Experiments with Synoptic-Scale Data". Mon. Wea. Rev. 118, pp 1250-1277 (1990).

11. Stauffer, D. R, and N. L. Seaman. "On Mesobeta-Scale Four Dimensional Data Assimilation". Preprints, Ninth Conf. on Numer. Wea. Pred., Amer. Met. Soc., pp 595-598, (1991).

12. Yamada, T., and T. Hermi. "A Four-Dimensional Data Assimilation of Airflows over Complex Terrain". Preprints, Ninth Conf. on Numer. Wea. Pred., Amer. Met. Soc., pp 603-606, (1991).

13. Fast, J. D., and B. L. O'Steen. Numerical Simulation of the Transport and Diffusion during the Winter Validation Study along the Front Range. WSRC-RP-92-160, Savannah River Site, Aiken, SC 29808 (1992).

14. Fast, J. D., and B. L. O'Steen. Use of the 1991 ASCOT Field Study Data in a Mesoscale Model Employing A Four-Dimensional Data Assimilation Technique. WSRC-RP-92-161, Savannah River Sire, Aiken, SC 29808 (1992). 
IBM RS/5000 workstation, model 550 UNIX operating system

Advanced ER System 1

- RAMS executed in semi-prognostic mode

- continuous data assimilation

- operational, updated hourly

- local transport calculations

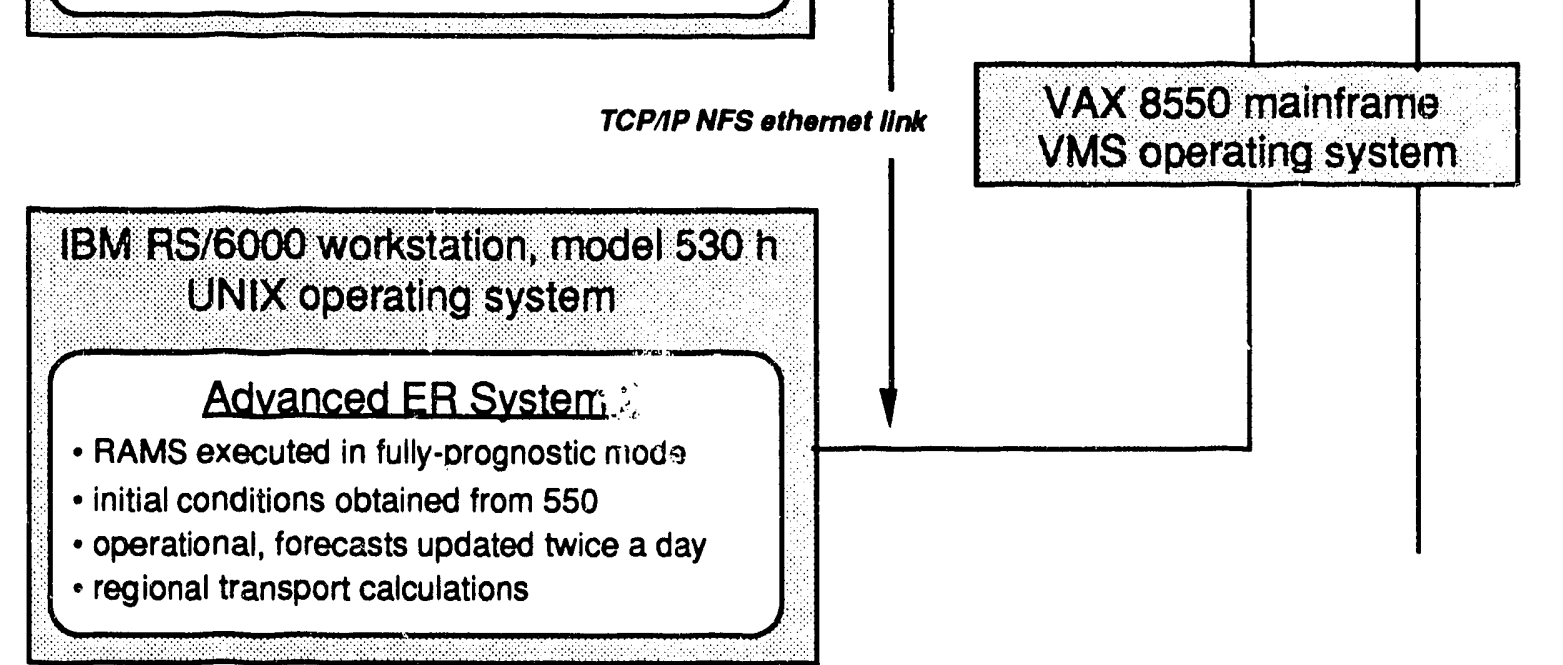

Fig. 1

Schematic diagram of the computational environment of the 3-D atmospheric/dispersion modeling capability 


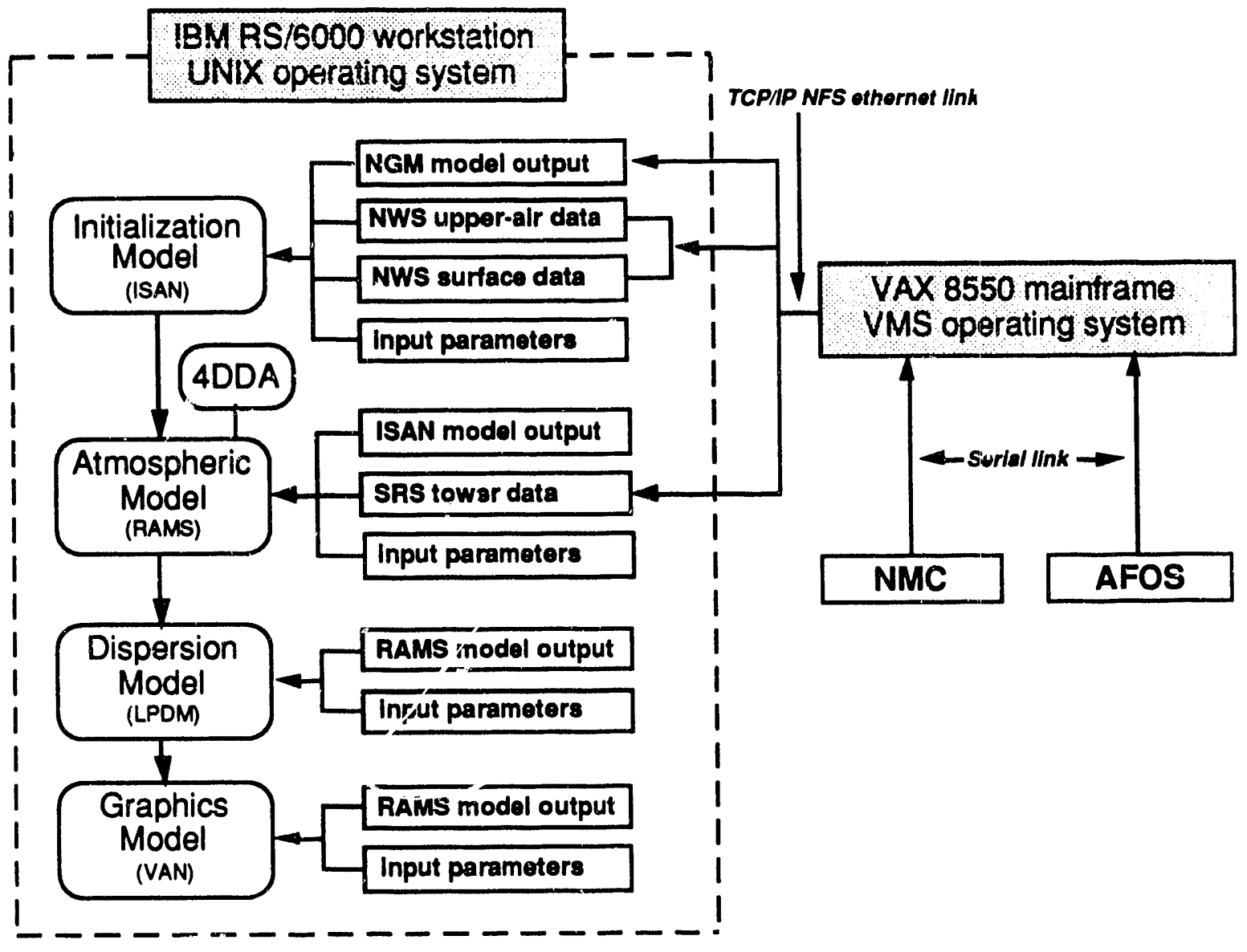

Fig. 2 Schematic diagram of the computational environment, observational data and model output, and individual modules of the 3-D atmospheric/dispersion modeling capability 


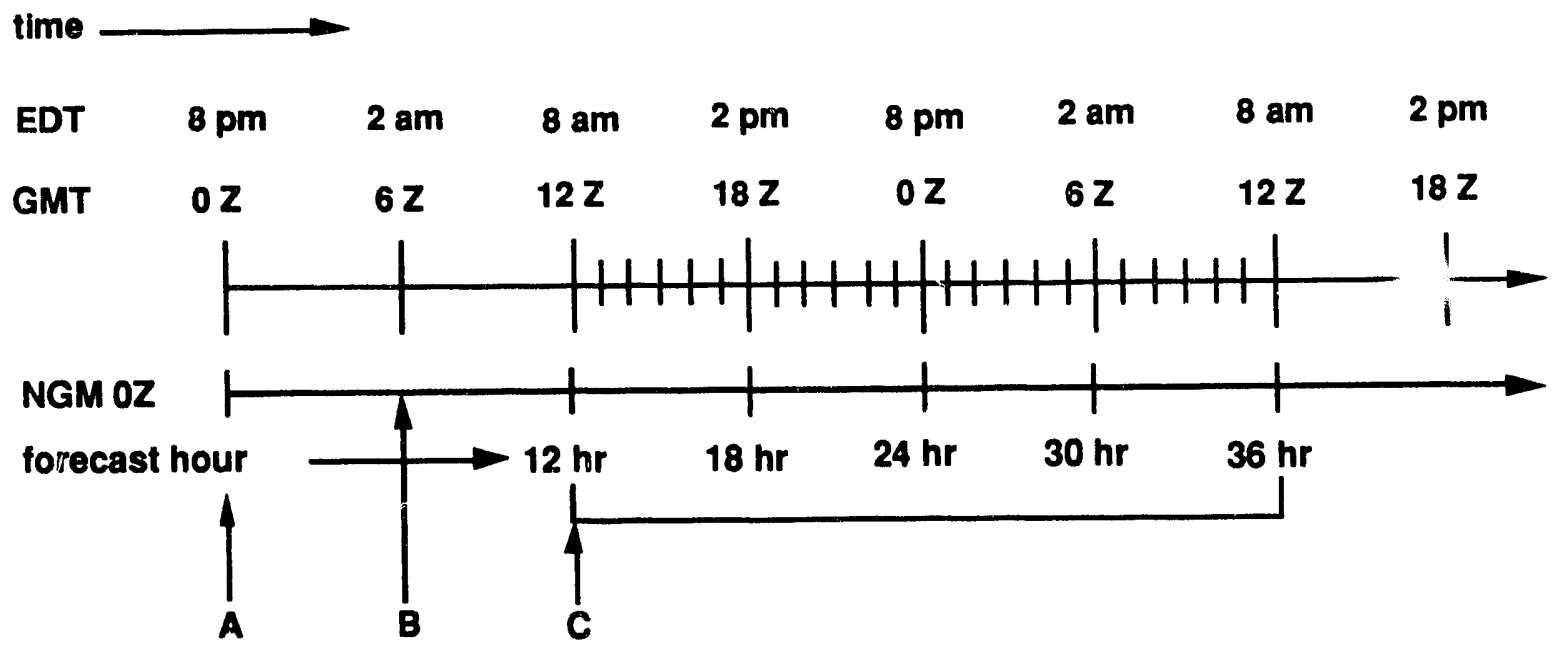
A - NGM $0 Z$ run initiated
B - NGM OZ output available and transmitted to VAX 8550 computer
C - RAMS run initiated

Fig. 3 Schematic diagram depicting the availability of the large-scale NGM model results and the cycle in which the RAMS model is run for the first operational mode of the advanced ER system 
(a)

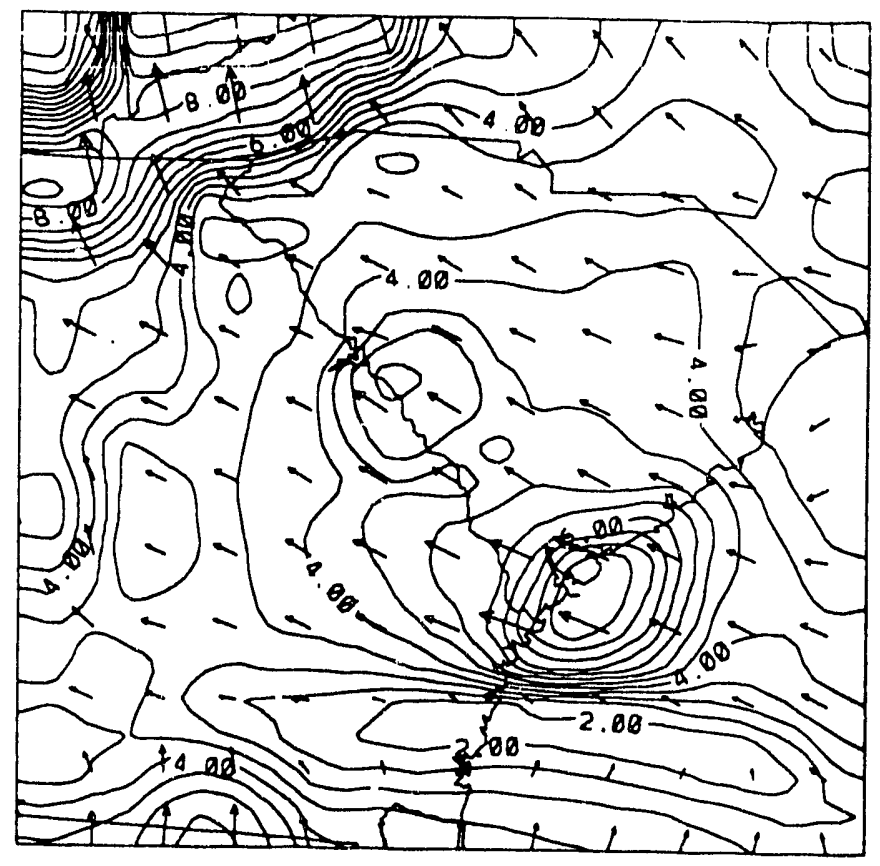

(b)

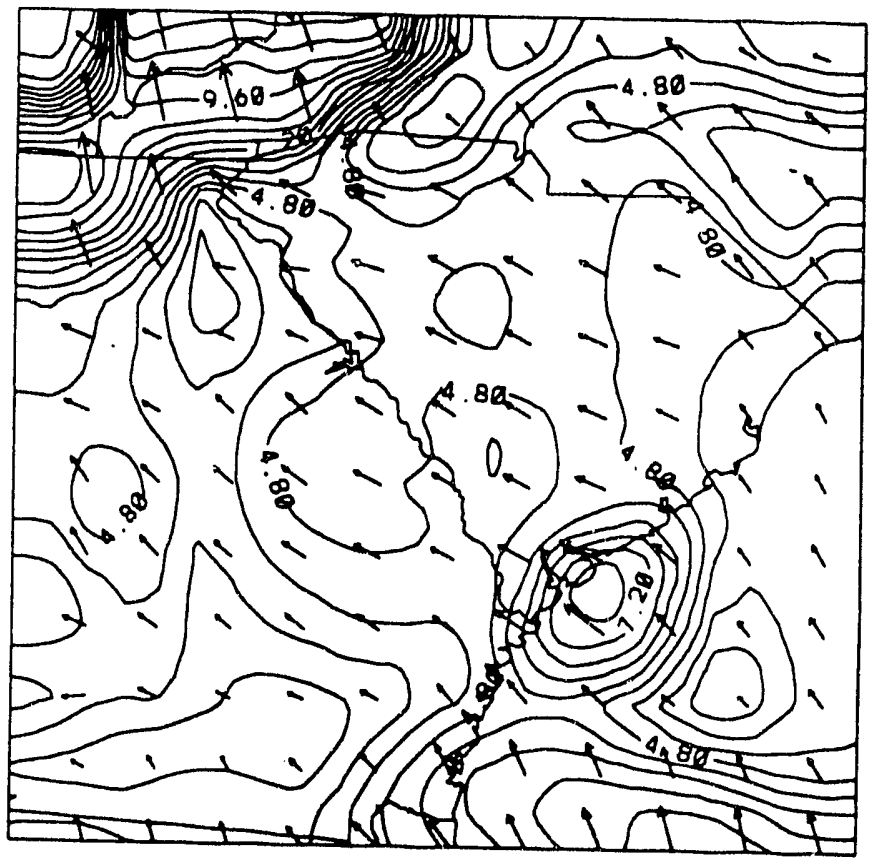

Fig. 4 Regional wind field determined by RAMS valid at (a) 2 pm and (b) 8 pm, June 3,1992 where the contours are wind speed in $\mathrm{m} \mathrm{s}^{-1}$ 
(a)

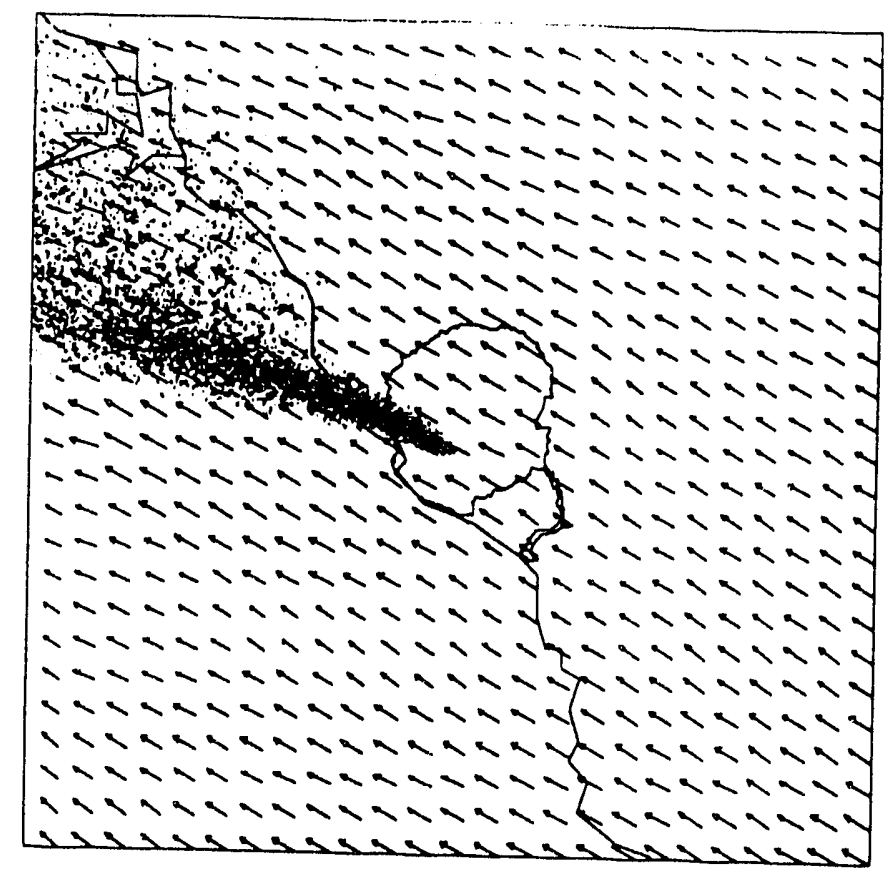

(b)

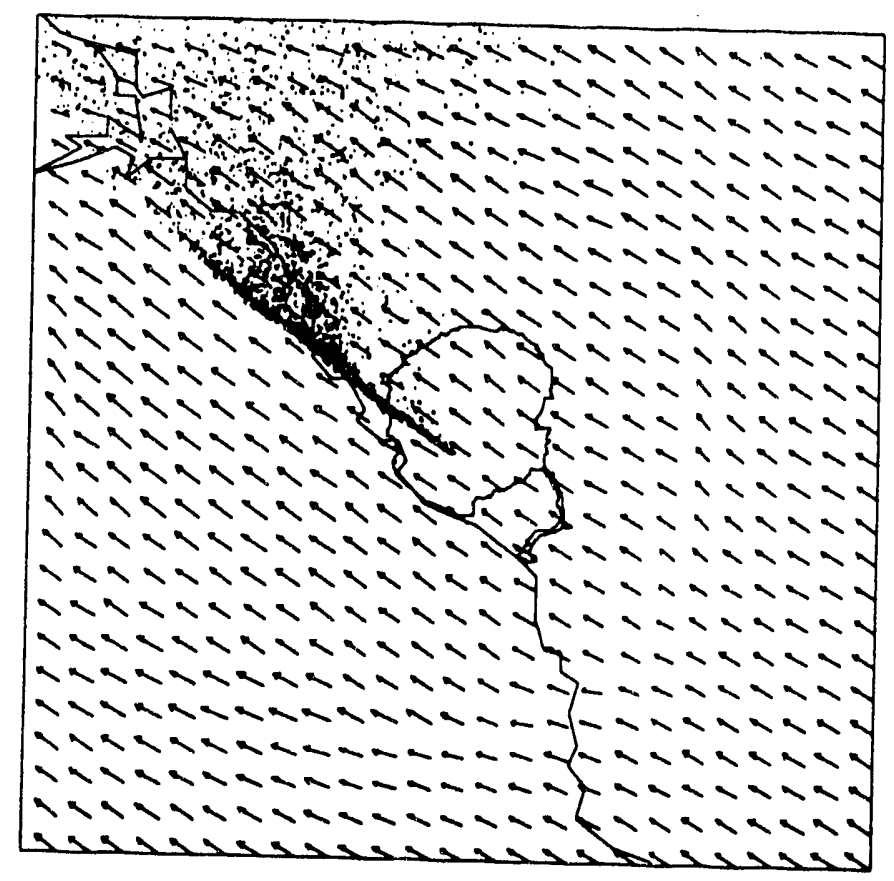

Fig. 5 Hypothetical plume from a release at K-Reactor predicted by LPDM valid at (a) 2 pm and (b) 8 pm, June 3, 1992 
(a)

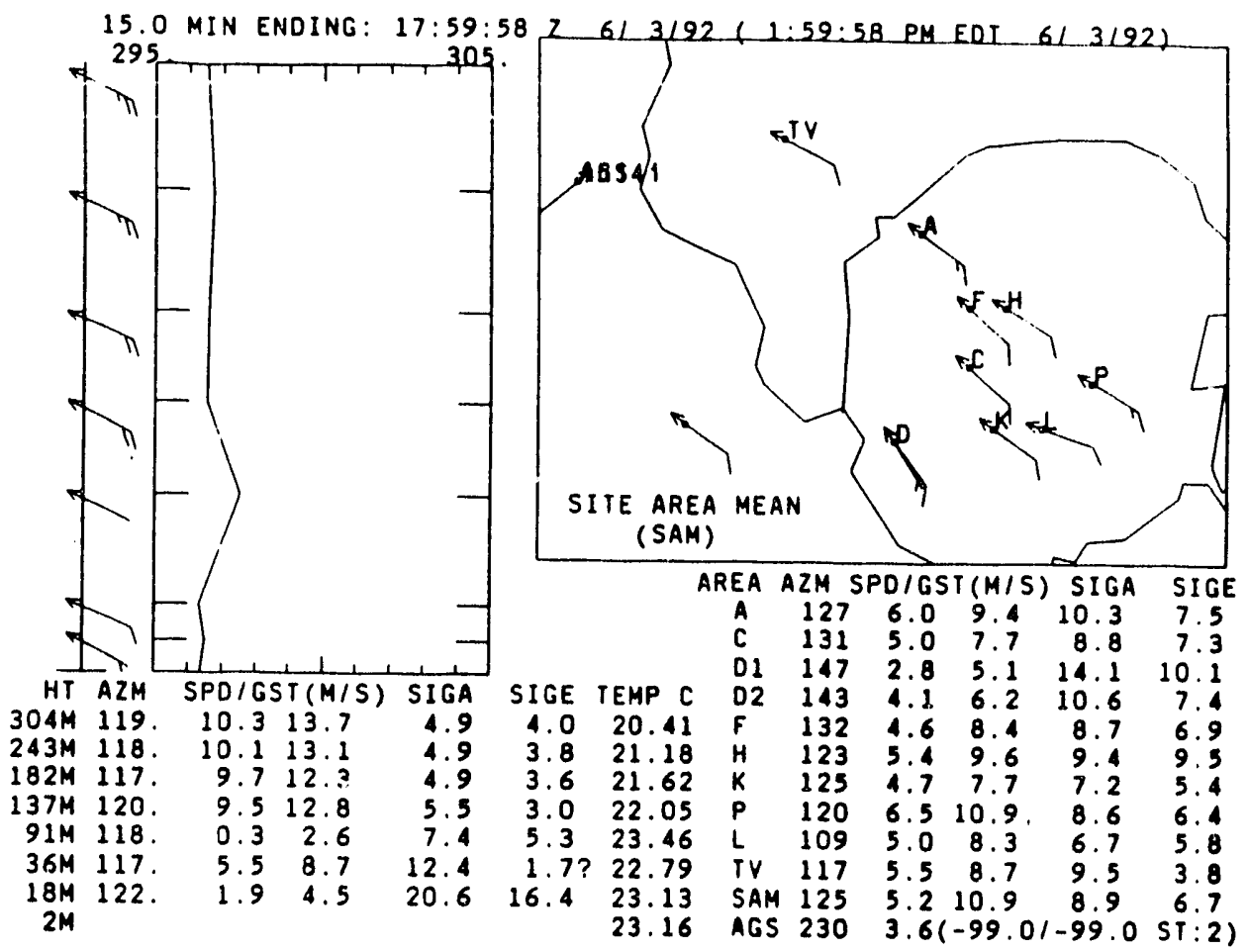

(b)

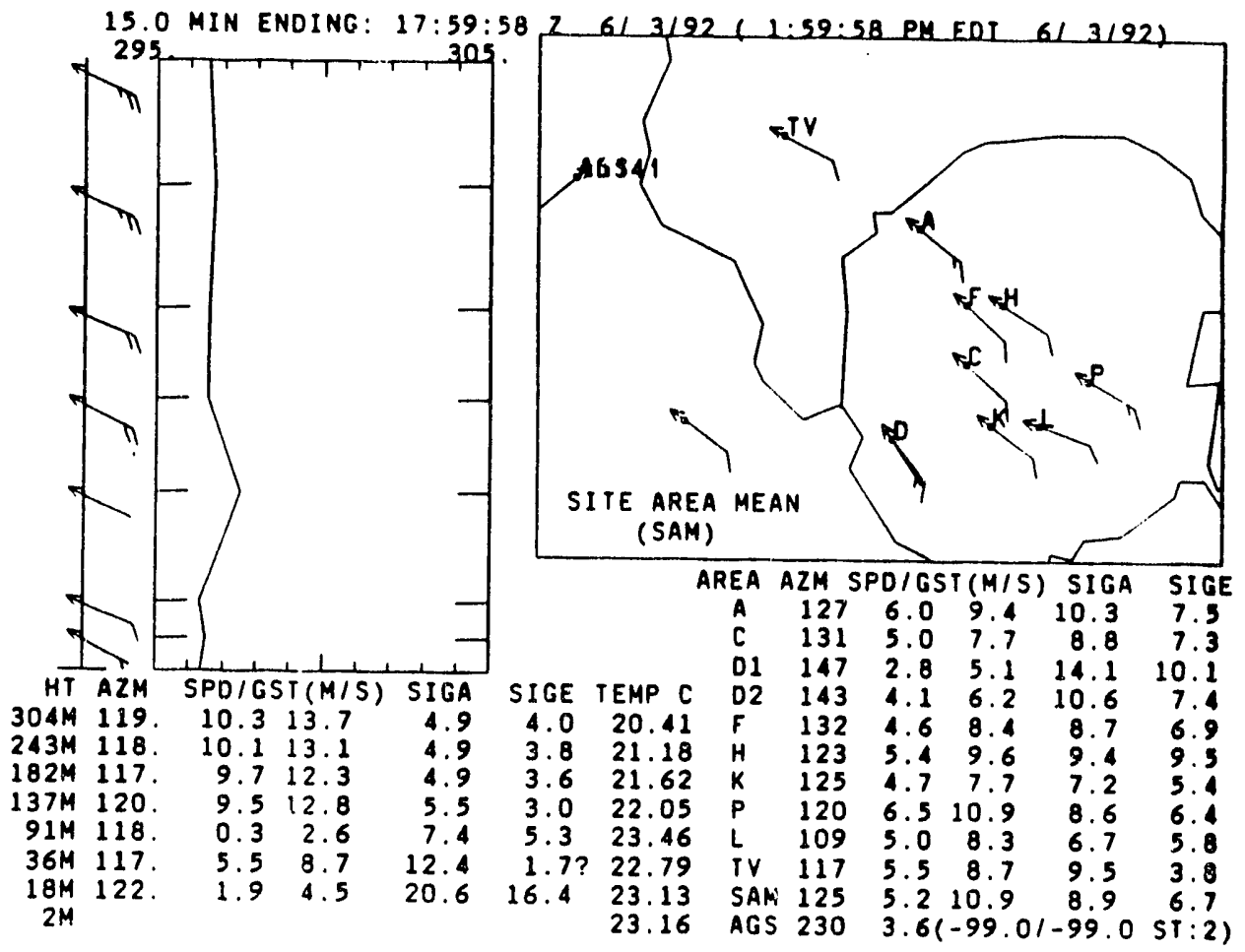

Fig. 6

Data from the SRS meteorological towers at (a) $2 \mathrm{pm}$ and (b) $8 \mathrm{pm}$, June 3, 1992 that was assimilated into the RAMS forecasts depicted in Figs. 4 and 5 

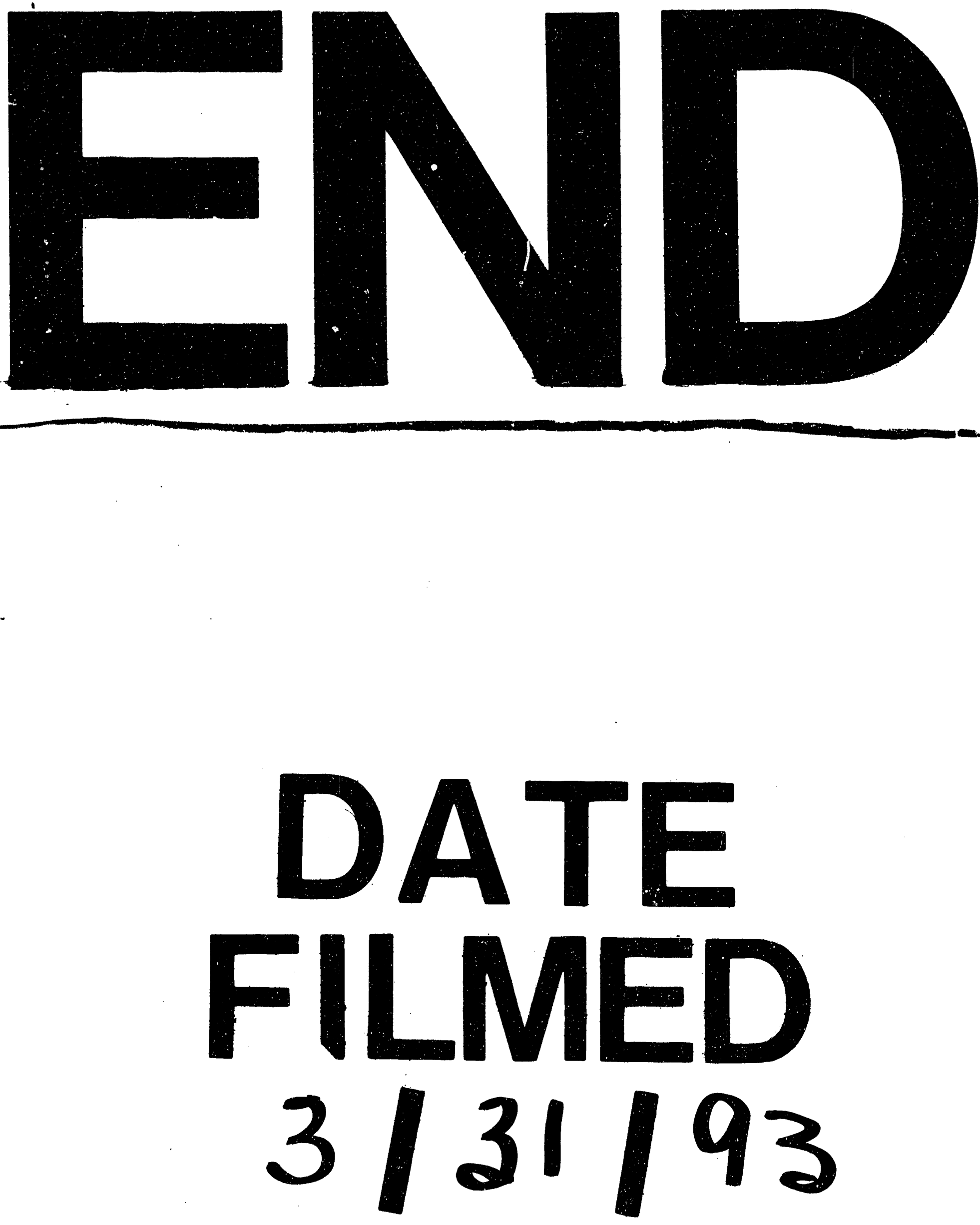
